\title{
Effects of high temperature stress and traits associated with tolerance in wheat
}

\begin{abstract}
Wheat (Triticum aestivum L.) is the most important crop in the world in terms of area harvested and the second most important food crop in the developing world after rice. To meet the increased demand of the exploding world population by 2050 , wheat production needs to increase by $60 \%$. However, wheat yields are currently limited by several environmental stresses, and high temperature stress is a major one among them. This review focuses on the impact of high temperature stress on wheat plants and traits associated with tolerance which would help formulate management strategies for wheat yield improvement under high temperature stress and breeding for high temperature tolerant varieties.
\end{abstract}

Keywords: Triticum aestivum, wheat plants, photosynthesis, wheat yield, tolerant varieties, biomass production high temperature stress
Volume 2 Issue 3 - 2018

Sruthi Narayanan
Assistant Professor, Clemson University, USA

Correspondence: Sruthi Narayanan, Assistant Professor, Clemson University, 212 Biosystems Research Complex, 105 Collings Street, USA, Tel 8646562419

Email skutty@clemson.edu

Received: May 21, 2018 | Published: May 252018
Abbreviations: PS II, photosystem II; CTD, canopy temperature depression; SS, starch synthase; SSS, soluble starch synthase; HSP, heat shock proteins; ROS, reactive oxygen species; $\mathrm{SG}$, sterol glycoside; $\mathrm{OH}$, hydroxyl ion; HIS, heat susceptibility index; TDF, time of day of flowering; TTC, triphenyl tetrazolium chloride

\section{Introduction}

Wheat (Triticum aestivum L.) is the most important crop in the world in terms of area harvested. ${ }^{1}$ It provides about $20 \%$ of the total dietary calories and proteins worldwide. ${ }^{1}$ It is a widely adapted crop grown in a vast range of environments ranging from temperate, irrigated areas to tropical, high-rainfall areas and from warm, humid conditions to cold, dry conditions. ${ }^{2}$ Wheat is one of the earliest domesticated food crops in the world ${ }^{3}$ and is believed to have originated in south-western Asia or more specifically, in the fertile crescent about 8000 to 10000 years ago. ${ }^{4}$ In recent years, wheat production levels were unable to meet the demand, leading to price instability and hunger riots. To satisfy the increased demand of 9 billion people by 2050 , wheat production needs to increase by $60 \%$. This will require at least $1.6 \%$ annual wheat yield increases, which in turn will necessitate tolerance to abiotic and biotic stresses and improved input use efficiency. High temperature stress is a major environmental factor that limits yield in wheat. Every $1{ }^{\circ} \mathrm{C}$ increase above a mean temperature of $23^{\circ} \mathrm{C}$ decreases wheat yield by $\sim 10 \% .{ }^{5}$ More than $40 \%$ of total wheat area in the world is affected by high temperature stress. ${ }^{6}$ High temperature affects wheat yield either through chronic stress by prolonged, moderately high temperatures up to $32^{\circ} \mathrm{C}$ or through heatshock, which is sudden, but comparatively brief exposure to $33^{\circ} \mathrm{C}$ and above. ${ }^{7-9}$ The impact of high temperature stress on crop depends up on intensity, rate of increase, duration of stress and stage of crop development. ${ }^{10,11}$ High temperature stress induces several alterations in physiological, biochemical and molecular components of wheat crop production. The objective of this review is to discuss the impact of high temperature stress on wheat plants and traits associated with tolerance which would help formulate management strategies for wheat yield improvement under high temperature stress and breeding for high temperature tolerant varieties.

\section{Effect of high temperature stress on physiological traits}

\section{Photosynthesis}

Photosynthesis is one of the most sensitive processes to high temperature in wheat. ${ }^{12}$ Photosynthetic rates exhibit a sharp decline when wheat plant is exposed to high temperature stress during vegetative or reproductive phase. ${ }^{12,13}$ Optimum temperature for photosynthesis has a broad range $\left(20\right.$ to $\left.30^{\circ} \mathrm{C}\right)$ in wheat, however, the rate photosynthesis declines rapidly at temperatures $>30^{\circ} \mathrm{C} .{ }^{14} \mathrm{Net}$ photosynthetic rate throughout the crop cycle is a major parameter controlling biomass production and grain yield of wheat under high temperature stress..$^{15,16}$ reported that high temperature $\left(32 / 27^{\circ} \mathrm{C}\right.$ day/ night) at seedling stage or from anthesis to maturity decreased average leaf photosynthetic rate of wheat by 32 and $11 \%$, respectively. ${ }^{17,18}$ reported reduction in photosynthetic rates due to high night temperatures $\left(>14^{\circ} \mathrm{C}\right)$ in wheat. Photosynthesis happening at awns is more temperature tolerant compared to that in leaves. ${ }^{19}$ Mobilization of stem reserves from pre-anthesis photosynthesis to developing grains is increasingly important for grain filling when current photosynthesis is inhibited by high temperature stress. ${ }^{9}$ Considerable genetic variability has been reported in wheat for net photosynthetic rate under high temperature conditions. ${ }^{20}$ Disruptions in the structure and function of chloroplasts, reduction in chlorophyll content and inactivation of chloroplast enzymes under high temperature are major reasons for decreased photosynthesis in wheat under high temperature stress. ${ }^{20,21}$ Reduction in net photosynthetic rate under high temperature stress during grain filling period is closely associated with chlorophyll loss ${ }^{9}$ and variation in the ratio between chlorophyll $a$ and chlorophyll $b$ due to premature leaf senescence. ${ }^{22,23}$ High temperature initially accelerates thylakoid membrane breakdown, which leads to electrolyte leakage and disruption of all photochemical reactions, especially, photosystem II (PS II) and cytochrome f/b6-mediated reactions, which ultimately lead to drastic reduction in rate of photosynthesis. ${ }^{22,23}$ Photosystem II has a major role in the responses of photosynthetic reactions to high temperature. Photosystem II is more sensitive to high temperature than PS I. ${ }^{24}$ In wheat, high temperature causes significant damage to 
different sites of PS II. ${ }^{25}$ Since wheat is a cool season crop, its PS II is more sensitive to high temperature stress compared to warm season crops such as rice and pearl millet (Pennisetum glaucum)..$^{22}$ High temperature stress also causes cessation of photophosphorylation due to damage of thylakoid membrane. ${ }^{26}$

\section{Stomatal conductance}

Increased stomatal conductance $\left(\mathrm{mmolm}^{-2} \mathrm{~s}^{-1}\right.$, measure of rate of $\mathrm{CO}_{2}$ entering or water vapor exiting through the stomata) leads to transpirational cooling and canopy temperature depression (CTD). Higher stomatal conductance and associated leaf cooling provides an avoidance type of heat resistance to high temperature. ${ }^{27,28}$ showed a positive correlation between stomatal conductance and yield in wheat grown under hot environments. identified stomatal conductance as a useful selection criterion in wheat for high yields. Positive correlation is reported between CTD and stomatal conductance and between CTD and yield in wheat grown under hot environments. ${ }^{28-30}$ reported that stomatal conductance remained unaffected across night temperatures of 14,17 and $20^{\circ} \mathrm{C}$ and slightly increased by $10 \%$ at night temperature of $23^{\circ} \mathrm{C}$.

\section{Respiration}

Impact of high temperature stress on respiration is relatively less understood. ${ }^{22}$ With increases in temperature, respiration cost increases and reaches the point that rate of photosynthesis cannot compensate for respiratory losses, and that leads to carbon starvation. ${ }^{31}$ Responses of respiration to high temperature vary with the age of organs in crop plants. ${ }^{27}$ Generally, respiration exponentially increases with increasing temperatures from 0 to 35 or $40^{\circ} \mathrm{C}$, reaches the maximum around 40 to $50^{\circ} \mathrm{C}$ and then decreases with further increases in temperature above $50^{\circ} \mathrm{C} .{ }^{32,33}$ reported high temperature $\left(35 / 25^{\circ} \mathrm{C}\right.$ day/night $)$ significantly increased the flag leaf respiration rates, compared to control $\left(23 / 18^{\circ} \mathrm{C}\right.$ day/night) in heat susceptible varieties.

\section{Effect of high temperature stress on biochemical traits}

\section{Enzyme activities}

Response of photosynthesis to high temperature stress is closely related to temperature dependence of the major photosynthetic enzyme, Rubisco. ${ }^{27}$ Under high temperature conditions, rate of inactivation of Rubisco exceeds activase's ability to promote Rubisco activation, ${ }^{34}$ which leads to reduced activation and activity of Rubisco. In addition, under high temperature stress, solubility of $\mathrm{CO}_{2}$ is decreased at a greater extent than $\mathrm{O}_{2}$, which favors the oxygenation activity of Rubisco, which leads to increased photorespiration and reduced photosynthesis. ${ }^{35}$ Endogenous levels of Rubisco activase plays an important role in determining wheat productivity under high temperature stress conditions. ${ }^{36}$ High temperature $\left(40^{\circ} \mathrm{C}\right)$ decreases the abundance of large and small subunits of Rubisco and Rubisco activase..$^{37,38}$ observed genetic variability in wheat for synthesis of the small subunit of Rubisco at $34^{\circ} \mathrm{C}$. Starch synthase (SS) is one of the key enzymes responsible for endosperm starch biosynthesis and grain filling. High temperatures above $25^{\circ} \mathrm{C}$ decrease the activity of SS in wheat. ${ }^{39-41}$ In addition, high temperature also regulates SS gene expression at the transcriptional level and reduces the relative levels of transcripts for that enzyme more than for other starch biosynthetic enzymes in wheat. ${ }^{39}$ Considering the enzymes involved in endosperm starch synthesis pathway, soluble starch synthase (SSS) is highly thermosensitive, especially at temperatures above $34^{\circ} \mathrm{C} .{ }^{40}$ Soluble starch synthase has a $\mathrm{T}_{\text {opt }}$ of $20-25^{\circ} \mathrm{C}$ and temperatures above $25^{\circ} \mathrm{C}$ adversely affect the activity of this enzyme, which results in reduced grain growth and starch accumulation. ${ }^{42}$ This effect is found to be apparently reversible in wheat after a short period of exposure to elevated temperature ${ }^{41}$ However, prolonged exposure to elevated temperature causes knockdown or complete loss of activity of SSS, which is much slower to reverse in wheat endosperm. ${ }^{41}$ Even short periods of high temperature stress $\left(30-40^{\circ} \mathrm{C}\right)$ causes a decline in the rate of starch deposition due to reduction in the activity of SSS. ${ }^{41}$ reported that several other enzymes in starch biosynthesis pathway, including alkaline pyrophosphatase, phosphoglucomutase, UDPglucose pyrophosphorylase, hexokinase, phosphoglucoisomerase, sucrose synthase, ADP- glucose pyrophosphorylase and bound starch synthase remained unaffected under elevated temperatures $\left(25-45^{\circ} \mathrm{C}\right)$.

\section{Membrane stability}

Membrane thermostability is highly correlated with yield in wheat under hot environments. ${ }^{43,44}$ Studies have documented high genetic variability and heritability of this trait in wheat. ${ }^{45}$ reported that membrane thermostability of heat-acclimated flag leaves under field conditions as well as seedlings grown in controlled conditions was associated with heat tolerance in 16 spring wheat cultivars at several hot environments. Level of unsaturation of membrane-phospholipids is linked to the extent of heat induced damage to membranes. ${ }^{46}$ Thylakoids harbor chlorophyll, and damage of thylakoid membrane under high temperature stress leads to chlorophyll loss in wheat ${ }^{47,48}$ reported increased membrane stability in heat tolerant wheat genotypes and association of that character to activity of antioxidant enzymes. Even though cell membrane thermostability has been identified as a potentially powerful selection criterion for high temperature tolerance in wheat, some studies have reported that this trait alone cannot serve for that purpose. ${ }^{49}$

\section{Heat shock proteins}

Plants produce specific proteins termed as heat shock proteins (HSP) in response to high temperature stress. Heat shock proteins are usually undetectable at non-stressed conditions. ${ }^{50}$ They can be categorized in to high molecular weight (ranges from 68 to $110 \mathrm{kD}$ ) and low molecular weight groups (ranges from 15 to $27 \mathrm{kD}$ ). High molecular weight HSPs are present in all organisms studied to date. Low molecular weight HSPs are the most abundant class of HSPs in higher plants, and the 15 to $18 \mathrm{kD}$ HSPs are unique to plants. ${ }^{50,51}$ Most, but not all, heat shock proteins are molecular chaperones. Molecular chaperones are proteins produced in plants in response to high temperature stress. ${ }^{52,53}$ They bind with partially unfolded or denatured proteins to stabilize them, and protect them from thermal aggregation and facilitate their re-folding during recovery when stress is relieved. ${ }^{54-56}$ Some HSPs are also involved in eliminating potentially harmful proteins arising from misfolding, denaturation or aggregation and play an important role in maintaining cellular homeostasis. ${ }^{57}$ Heat shock proteins consists of classical and non-classical proteins. Most of the classical HSPs exhibit chaperon activity, binding with denatured proteins to prevent their thermo-aggregation. Non-classical HSPs include plastid protein synthesis elongation factor EF-Tu and peptidyl-prolyl cis/trans isomerases.$^{47}$ showed a positive correlation between synthesis of specific low molecular weight HSPs and heat tolerance in wheat. Wheat exhibits genetic variability for the synthesis of HSPs in response to high temperature stress. ${ }^{38-57}$ reported that acquired heat tolerance in wheat is associated with the level of expression of HSP genes during the initial $2 \mathrm{~h}$ of high temperature stress. It is reported that HSPs are synthesized even before leaf 
temperatures reach lethal levels for growth and development. ${ }^{58,59}$ reported that EF-Tu is upregulated in wheat under high temperature stress and genotypes with increased accumulation of this protein are tolerant to high temperature stress. EF-Tu improves heat tolerance through its chaperone activity. ${ }^{60}$ reported that transgenic wheat carrying an EF-Tu gene from maize (Zea mays L.) exhibited decreased thermal aggregation of leaf proteins and thylakoid membrane damage and increased rate of photosynthesis under high temperature stress. Transgenic wheat plants with EF-Tu gene produced superior grain yield based on number of grains per plant, total grain weight per plant and individual grain weight, compared to their non-transgenic counterparts under high temperature stress (Fu and Ristic, 2010). Modification of the expression of plastidal EF-Tu and/or selection of genotypes with increased activity might help improve heat tolerance of wheat. ${ }^{60}$

\section{Reactive oxygen species}

High temperature stress often induces accumulation of reactive oxygen species (ROS) including hydrogen peroxide $\left(\mathrm{H}_{2} \mathrm{O}_{2}\right)$, superoxide radical $\left(\mathrm{O}_{2}^{-}\right)$, hydroxyl ion $\left(\mathrm{OH}^{-}\right)$and singlet oxygen $\left(\mathrm{O}^{-}\right.$ $\left.{ }^{1}\right)$ in plant tissues, which leads to oxidative stress. ${ }^{61,62}$ Chloroplast, mitochondria and peroxisomes are major cellular organelles that generate ROS under stress. ${ }^{63-65}$ High temperature stress induced membrane and protein damage results in increased ROS content. ${ }^{66,67}$ Over-excitation of chlorophyll molecules under high temperature also results in accumulation of ROS ${ }^{68-70}$ In general, high temperature induced imbalance between photosynthesis and respiration leads to oxidative damage in plants. ${ }^{71}$ Accumulation of ROS causes disruption of DNA strands and activation of cell wall hydrolyzing enzymes such as nucleases, proteases and lipases resulting in loss of cell structure. ${ }^{72,73}$ It also causes denaturation of proteins and lipid peroxidation in membranes, which lead to membrane damage and membrane leakiness, and ultimately results in decreased photosynthetic rate and enhanced cell death. ${ }^{74,75}$

\section{Antioxidants}

The antioxidant defense system in plants has both enzymatic and non-enzymatic components. Major antioxidant enzymes in plants include superoxide dismutase, catalase, peroxidase, ascorbateglutathione pathway enzymes such as ascorbate peroxidase, monodehydroascorbate reductase, dehydroascorbate reductase and glutathione reductase, Halliwell-Asada pathway enzymes and dehydroascorbate reductase. Non-enzymatic antioxidants include glutathione, ascorbic acid, $\beta$-carotene and tocopherols. Under nonstressed conditions, antioxidants scavenge ROS and protect cells from oxidative damage. Under stressed conditions, the general antioxidant status diminishes or antioxidants reduce their activity and the amount of ROS increases in the cell. ${ }^{76-78}$ Superoxide dismutase, catalase and peroxidase system converts ROS to $\mathrm{O}_{2}$ and water. As a result of ascorbate-gluthatioine pathway, $\mathrm{H}_{2} \mathrm{O}_{2}$ will be reduced to water. Superoxide dismutase is the only enzyme that can scavenge $\mathrm{O}_{2}^{-}$, whereas catalase and peroxidase scavenge $\mathrm{H}_{2} \mathrm{O}_{2}$. Increased antioxidant enzyme (superoxide dismutase, catalase, glutathione reductase and peroxidase) activities are reported in heat tolerant genotypes in wheat. ${ }^{79,80}$ Non-enzymatic antioxidants, such as ascorbic acid is also important for protection of wheat plants from heat-induced oxidative damage ${ }^{81,82}$ found that application of abscisic acid and salicylic acid increased the activity of antioxidant enzymes and decreased the amount of ROS in high temperature stressed wheat plants, and this decreased oxidative damage resulted in increased chlorophyll and carotenoid contents, relative water content, membrane stability index, leaf area and total biomass compared to control plants.

\section{Effect of high temperature stress on lipid metabolism}

Identified lipid metabolic changes ${ }^{83-85}$ during high temperature stress in wheat and coordinated metabolism of lipid groups during high temperature stress responses ${ }^{83-85}$ they found that wheat leaf and pollen lipid compositions are significantly altered by high temperatures, in which some lipids are highly responsive to high temperatures, and that two wheat genotypes, chosen for their differing physiological responses to high temperature, differ in leaf lipid profiles under high temperatures. The wheat plants decreased the unsaturation levels of plastidic and extraplastidic glycerolipids of leaf and/or pollen in order to adapt to high temperature stress, and underwent lipid remodeling, likely to prevent the phase transition of membranes from a bilayer to non-bilayer phase. The lipid remodeling included decreases in the amount of more unsaturated lipids and increases in the amounts of less unsaturated lipids, phospholipids containing odd-chain fatty acids, sterol lipids [sterol glycoside (SG) and 16:0 acyl containing SG], 18:3-acyl-containing TAGs, and ox-lipids. Increases in activities of desaturating, oxidizing, glycosylating, and acylating enzymes led to simultaneous changes in levels of multiple lipid species during stress, leading to existence of co-occurring lipid groups. ${ }^{84}$ Their results suggested that (1) SGs and ox-lipids might be associated with plant heat tolerance and susceptibility, respectively, (2) TAGs play a role in high temperature stress adaptation by sequestering fatty acids from the membrane lipids, and (3) changes in the amounts of phospholipids with odd-chain fatty acyl components under high temperature stress might be a diagnostic of the extent of heat damage, and (4) lipids can undergo coordinated metabolism during high temperature stress, leading to existence of co-occurring lipid groups.

\section{High temperature sensitive stages in wheat}

\section{Vegetative stages}

High temperature, usually, decreases the duration of all growth stages in wheat. ${ }^{86}$ reported that high temperature from emergence to anthesis significantly decreased duration of all the development stages, GS1 (emergence to double-ridge), GS2 (double ridge to anthesis) and GS3 (anthesis to grain maturation) in wheat; and duration of GS2 was most sensitive to high temperature. The developmental stage at which wheat plant is exposed to high temperature stress will determine the degree of damage. ${ }^{87}$ The double-ridge stage is highly sensitive to high temperature stress ${ }^{87}$ High temperature at double-ridge stage damages the development of spikelet primordia on the apex. ${ }^{88}$ reported that plant height and tiller number remained unaffected, whereas, biomass showed a curvilinear decrease under high night temperatures $\left(>23^{\circ} \mathrm{C}\right)$ in wheat.

\section{Reproductive stages}

High temperature stress during reproductive development is a major constraint to wheat production in most parts of the world. Wheat plant suffers from greater damage when high temperature stress occurs during the reproductive phase than vegetative phase due to the direct effect of high temperature on grain number and grain weight. ${ }^{89}$ Generally, plant reproductive tissues have less temperature tolerance compared to vegetative tissues. Reproductive development is accelerated when wheat is grown in hot environments..$^{90,91}$ 


\section{Pollen and ovule formation}

The most heat sensitive stage of reproductive development in wheat is the period from the onset of meiosis in pollen or embryo sac mother cells to the early development of micro or megaspores. ${ }^{92-94}$ Pollen formation is one of the most heat sensitive processes in cereals including wheat. ${ }^{92-94}$ High temperature induced pollen sterility is mainly due to the irregularities during microsporogenesis. ${ }^{95}$ Inability of pollen to synthesize HSP is thought to be the reason for its increased sensitivity to high temperature ${ }^{92-95}$ reported $35 \%$ reduction in pollen viability in wheat plants exposed to high temperature of $30^{\circ} \mathrm{C}$ for $3 \mathrm{~d}$ compared to normal temperature $\left(20^{\circ} \mathrm{C}\right)$. Female fertility is also affected by high temperature in wheat. ${ }^{92-94}$ High temperature stress that coincides with meiosis in megaspore mother cells leads to abnormal ovary development with small sized or no embryo sac and reduced nucellus. ${ }^{93}$ High temperature stress causes many ultrastructural changes to pollen grains which lead to pollen sterility in wheat..$^{93}$ reported that high temperature $\left(30^{\circ} \mathrm{C}\right.$ for $\left.3 \mathrm{~d}\right)$ during meiosis caused premature degeneration of tapetal cells which resulted in pollen sterility in wheat. These sterile pollen grains contained apparently normal exine, very little or no intine or cytoplasm and no starch.

\section{Anthesis}

High temperature stress causes severe damage to plants when it occurs during or soon after anthesis. Wheat plants are highly susceptible to high temperature stress during the period between flower initiation and anthesis, and the effect is marked by the reduction in kernel number. $\mathrm{T}_{\text {min }}, \mathrm{T}_{\mathrm{opt}}$ and $\mathrm{T}_{\max }$ for successful anthesis are reported as $9,18-24$ and $31^{\circ} \mathrm{C}$ respectively in wheat. ${ }^{97}$

\section{Seed set}

Generally, high temperature stress just before or during anthesis is associated with reduced seed set percentage in wheat, mainly due to (a) production of nonviable pollen or ovule, (b) hindered pollen tube growth and (c) inability of fertilized embryo-sac for the transition to a seed. ${ }^{92-94}$ Seed set in wheat is most sensitive to high temperature stress when the stress coincides with the time period between the onset of meiosis in pollen mother cell to the formation of microspores and their early development. ${ }^{92-94}$ High temperature stress at this highly sensitive stage hinders pollen performance, which leads to drastic reduction in seed set. High temperature stress during meiosis in megaspore mother cell results in abnormal ovary development and reduced pollen tube growth in wheat, which leads to reduced seed set. Embryo abortion has been reported in wheat due to high temperature stress. ${ }^{98}$ reported that high temperature induced increase in ethylene production presumably causes embryo abortion and decreased kernel weight in wheat.

\section{Yield components and yield}

\section{Grain number}

Grain number is a major component of yield in wheat. ${ }^{99}$ High temperature accelerates the development of the spike and reduces the number of spikelets and grains per spike. ${ }^{21}$ Genetic variation is reported in wheat for grain number under high temperature stress. ${ }^{44,45}$ Temperatures above $31^{\circ} \mathrm{C}$ just before anthesis cause reduction in grain number due to pollen sterility. ${ }^{100}$ reported $4 \%$ reduction in number of wheat grains per unit area for each degree increase (from $15-22^{\circ} \mathrm{C}$ ) in mean temperature during the one month period before anthesis. reported that $10^{\circ} \mathrm{C}$ increase in maximum temperature at mid anthesis caused $40 \%$ reduction in grain number per spike. ${ }^{101-103}$ examined 21 spring wheat cultivars and found that heat tolerance was associated with increases in grain number per spike documented a linear decrease in grain number per spike with increases in night temperatures from 14 to $23^{\circ} \mathrm{C}$.

\section{Individual grain weight}

Reported that high temperature $\left(32 / 27^{\circ} \mathrm{C}\right)$ from anthesis to maturity caused $20 \%$ reduction in average grain weight of wheat. ${ }^{104}$ observed that high temperature $\left(40 / 21^{\circ} \mathrm{C}\right)$ during grain filling decreased individual grain weight of wheat by $14 \%$, compared to the control $\left(21 / 16^{\circ} \mathrm{C}\right) .^{5}$ imposed high temperature stress starting from 15 $\mathrm{d}$ after anthesis (grain number was set by this time) until maturity, and quantified yield reduction due to decreased individual grain weight as $18 \%$. Elevated temperatures reduce the time period between anthesis and physiological maturity, which results in a reduction in individual grain weight. ${ }^{105}$ Decreased size of endosperm cells in grains and reduced starch deposition due to reduced activity of SSS are major reasons for decreased individual grain weight under high temperature stress. ${ }^{106}$ reported that a sudden increase in temperature (from 20 to $40^{\circ} \mathrm{C}$ ) caused a greater reduction in individual grain weight than a gradual increase in temperature $\left(6^{\circ} \mathrm{C} \mathrm{h}^{-1}\right.$, from 20 to $\left.40^{\circ} \mathrm{C}\right)$ in a heat sensitive wheat variety, but this trend was absent in the heat tolerant wheat variety. Considerable genetic variability has been identified in wheat for individual grain weight under high temperature stress.

\section{Grain filling duration}

High temperature-induced decrease in grain filling duration results in a reduction of individual grain weight. ${ }^{84-104}$ Grain filling duration decreases by $2-8 \mathrm{~d}$ for every $1{ }^{\circ} \mathrm{C}$ increase above $15-20^{\circ} \mathrm{C}$ in wheat (reviewed by Streck, 2005). Prasad et al. (2008b) reported that grain filling duration in wheat was decreased by 3 and $7 \mathrm{~d}$ at night temperatures of 20 and $23^{\circ} \mathrm{C}$, respectively, compared to a night temperature of $14^{\circ} \mathrm{C}$.

\section{Grain filling rate}

Under optimum temperature conditions, decreased grain filling duration is compensated by increased grain filling rate, but this compensation does not happen under high temperature stress, which results in a significant reduction in individual grain weight. ${ }^{107}$ Reduction in leaf and spike photosynthesis and decreased remobilization of stem reserves are major reasons for decreased grain filling rate at high temperatures. Increased grain filling rate is a useful trait that can be used for the improvement of heat tolerance in wheat. ${ }^{26}$

\section{Total grain yield}

Found that high temperature stress of $35 / 20^{\circ} \mathrm{C}$ from $10 \mathrm{~d}$ after anthesis until maturity decreased grain yield by $78 \%,{ }^{5}$ grain number by $63 \%$ and individual grain weight by $29 \%$. Reduction in number of spikes per unit area, number of fertile spikes per plant, number of grains per spike and grain weight lead to reduction in grain yield of wheat under high temperature stress. ${ }^{108}$ reported that grain yield in wheat is more sensitive to increases in daily $\mathrm{T}_{\min }$ than $\mathrm{T}_{\max }$. The same authors observed $10 \%$ decrease in wheat yield for every $1^{\circ} \mathrm{C}$ increase in night temperature above optimum in Mexico.

\section{Grain quality}

High temperature stress during the post-heading period adversely affects grain quality in wheat. ${ }^{103}$ High temperature stress influences grain protein content and composition. ${ }^{102}$ It reduces starch deposition 
in grains ${ }^{109}$ and leads to more nitrogen per unit of starch. ${ }^{41}$ High temperatures $\left(>35^{\circ} \mathrm{C}\right)$ during grain filling negatively affect dough properties in wheat since it increases the ratio between gliadin and glutenin in grains, which produces a weak dough (Blumenthal et al., 1993). High temperature stress also reduces noodle swelling power of wheat flour (Stone and Nicolas, 1994).

\section{Breeding for high temperature tolerance}

Genetic resources available for the improvement of bread wheat consist of primary, secondary and tertiary gene pools. ${ }^{110}$ Genetic variability for heat tolerance has been identified in cultivated wheat ${ }^{111-114}$ and its wild relatives. ${ }^{115,116}$ Genetic variability for heat tolerance has been reported in wild Triticum and Aegilops species as well. These authors tested accessions from nine different countries of the world and found that all of the heat tolerant accessions were from eastern Israel, western Jordan and southwestern Syria. The authors also suggested that these three regions can be exploited for heat tolerant genotypes of bread and durum wheat that could be incorporated into wheat breeding programs. Landraces also exhibit significant genetic variability for heat tolerance. Heat tolerant accessions belonging to Aegilops geniculata, A. speltoides, A. searsii and A. longissima have been identified. ${ }^{117}$ screened 52 accessions of Aegilops sp. for tolerance to an extended period (16d) of high temperature stress at anthesis and identified tolerant genotypes of A. speltoides and A.geniculata based on grain number and grain size. They also reported that tremendous genetic variability exists in Aegilops $s p$. for heat tolerance that can be exploited in breeding for heat tolerance at reproductive stage. High temperature tolerance have also been reported in different genotypes of synthetic wheat. ${ }^{118,119}$ Synthetic wheats are valuable genetic stocks and can act as bridges for introgression of alien genes into cultivated wheat varieties. ${ }^{120,121}$

\section{Traits associated with heat tolerance}

\section{Canopy temperature depression}

Canopy temperature depression is the difference between air temperature and canopy temperature. Canopy temperature depression shows high genetic correlation with yield in wheat in both warm and temperate environments. Canopy temperature depression is significantly correlated with biomass, grains $\mathrm{m}^{-2}$, spikes $\mathrm{m}^{-2}$ and grains spike $^{-1}$ under high temperature conditions in wheat. It is a heritable trait and can serve as a useful criterion for evaluating heat tolerance in both early and advanced generations. Canopy temperature depression is a function of many important physiological mechanisms such as metabolism, partitioning and vascular transport, and is therefore, a powerful trait for selection. However, this trait is highly sensitive to environmental factors such as radiation, evapotranspiration and wind. It shows highest potential as a selection criterion in low relative humidity environments.

\section{Early heading}

Early heading is an important and effective trait of wheat genotypes that contribute to heat tolerance. ${ }^{122}$ concluded that earlyheading cultivars out-yielded later-heading cultivars in environments with risks of post-heading high temperature stress. Compared to later heading cultivars, early heading cultivars showed many important tolerant traits including (a) longer post-heading period and grainfilling duration, (b) completion of significant fraction of grain-filling duration earlier in the season before the onset of high temperature stress, (c) retention of more number of green leaves at anthesis and (d) less number of leaves lost due to senescence at anthesis. However, early heading may not be a useful trait to select cultivars suitable for locations where cool temperature or frost limits the early heading trait.

\section{Time of day of flowering}

Another dehiscence, pollen shed, pollen tube growth, pollination and fertilization are highly sensitive to high temperature stress, while the embryo formed after fertilization is comparatively more tolerant. The time of day of flowering (TDF) is the time of the day at which anthesis commences in a crop. ${ }^{123}$ Air temperature increases rapidly after sunrise and exceeds the critical temperature of $35^{\circ} \mathrm{C}$ at around 10:00 AM in high temperature damage-prone areas. ${ }^{124}$ Therefore, shifting of TDF to early hours of the morning is one way to escape high temperature- induced spikelet sterility in plants. ${ }^{124}$ Genetic variability has been reported for TDF in cereals such as rice, where TDF varied from 7:00 AM to 12:30 PM.

\section{Increased partitioning}

Grain filling under high temperature stress is largely associated with partitioning of stem reserves in wheat. Increased ability to utilize mobilized stem reserves contributes to increased grain number and grain weight under high temperature stress. Increased partitioning of reserves from leaves, stem or other plant parts is a potential strategy to improve grain filling and yield in wheat under high temperature stress. Considerable genetic variability is reported for assimilate partitioning under high temperature stress in wheat. Increased partitioning under high temperature stress is a 'true tolerance mechanism' exhibited by tolerant genotypes.

\section{Heat susceptibility index}

Heat susceptibility index (HSI) for grain yield is calculated using the formula, $\mathrm{HSI}=(1-\mathrm{Y} / \mathrm{Yp}) / \mathrm{D}$; where, $\mathrm{Y}$ is the average grain yield per plant of a genotype at high temperature, $\mathrm{Yp}$ is the average grain yield per plant of the same genotype at optimum temperature, $\mathrm{D}$ is the stress intensity, which is calculated as $1-\mathrm{X} / \mathrm{Xp}$, in which $\mathrm{X}$ is the mean $\mathrm{Y}$ of all genotypes, and $\mathrm{Xp}$ is the mean $\mathrm{Yp}$ of all genotypes. ${ }^{125}$ Low HSI is a useful criterion to select heat tolerant genotypes in cultivated and wild wheat. Generally, genotypes with $\mathrm{HSI} \leq 0.5$ are considered as highly heat tolerant, genotypes with $\mathrm{HSI}>0.5$ to $\leq 1.0$ are considered as moderately tolerant and genotypes with HSI $>1.00$ are considered as susceptible.

\section{Chlorophyll content}

Measurement of chlorophyll content in leaves is useful for high throughput screening for heat tolerance among wheat genotypes. ${ }^{47}$ Chlorophyll loss is closely associated with heat-induced thylakoid membrane damage in wheat. ${ }^{47}$ Genetic variability exists in wheat for the ability to retain chlorophyll content under high temperature stress. ${ }^{125}$

\section{Decreased membrane damage}

Increased membrane stability, which is an indication of decreased membrane damage is a selection criterion used to select heat tolerant wheat genotypes under both controlled and field conditions. Genotypes vary in the extent of membrane damage under high temperature stress. Since cellular membrane stability is a highly heritable trait, it has a potential application in breeding wheat for heat tolerance. found that increased membrane stability was associated with 
increased grain weight per spike in wheat. Measurement of electrical conductivity quantifies heat induced electrolyte leakage from tissues, thus, it evaluates the damage to plasma membrane measurement of chlorophyll $a$ fluorescence indicates damage to thylakoid membranes specifically; ${ }^{126}$ and triphenyl tetrazolium chloride (TTC) assay can quantify damage to mitochondrial membranes. ${ }^{127-130}$

\section{Decreased ROS production and increased amount of antioxidants}

Protection against oxidative damage is an important component in the determination of heat tolerance in plants. ${ }^{131-134}$ Increased antioxidant activity is correlated with reduced oxidative damage and acquired thermotolerance in wheat. The beneficial effects of increased antioxidant enzyme activity and decreased oxidative damage is reflected in many physiological and biochemical parameters such as increased chlorophyll and carotenoid contents, relative water content and membrane stability and whole plant characteristics such as increased leaf area and total biomass. To exploit the association between antioxidant activity and heat tolerance, external growth regulators are applied in wheat to increase the activity of antioxidants and to reduce heat damage. ${ }^{135-137}$ For example, ${ }^{137-142}$ abscisic acid and salicylic acid when sprayed on leaves of wheat genotypes increase the activity of antioxidant enzymes such as superoxide dismutase, ascorbate peroxidase, ${ }^{142-145}$ glutathione reductase and catalase and decrease the contents of ROS such as hydrogen peroxide and thiobarbituric acid reactive substances. ${ }^{64}$

\section{Heat Shock Proteins}

Since the synthesis of HSPs is related to acquisition of heat tolerance in wheat, ${ }^{54,55}$ it offers a useful trait for selecting for heat tolerance. Manipulation of expression patterns of HSPs has the potential to improve temperature tolerance of wheat. Transgenic wheat plants with increased heat tolerance have been developed using HSP (plastid protein synthesis elongation factor- EF-Tu genes from maize. ${ }^{145-148}$

\section{Acknowledgements}

None.

\section{Conflict of interest}

The author declares there is no conflict of interest.

\section{References}

1. FAO. FAOSTAT, FAO, Rome, Italy; 2018. p. 1-2.

2. Acevedo E, Silva P, Silva H. Wheat growth and physiology. In: BC Curtis, et al. editors. Bread wheat Improvement and production. FAO, Rome, Italy; 2002. p. 39-70.

3. Curtis BC, Wheat in the world. In: Curtis BC, et al. editors. Bread wheat improvement and production. FAO, Rome, Italy; 2002. p.1-17.

4. Jiang J, Friebe B, Gill BS. Recent advances in alien gene transfer in wheat. Euphytica. 1994;73:199-212.

5. Gibson LR, Paulsen GM. Yield components of wheat grown under high temperature stress during reproductive growth. Crop Sci. 1999;39(6):1841-1846.

6. Hede AR, Skkovm B, Reynolds MP, et al. Evaluating genetic diversity for heat tolerance traits in Mexican wheat landraces. Genet Res Crop Evol. 2001;46:37-45.
7. Paulsen GM. High temperature responses of crop plants. KJ Boote editor. Physiology and determination of crop yield. ASA, CSSA, and SSSA, Madison, WI; 1994. p. 365-389.

8. Savin R, Stone PJ, Nicolas ME, et al. Grain growth and malting quality of barley. Effects of high temperature stress and moderately high temperature. Aust J Agric Res. 1997;28:616-624.

9. Yang J, RG Sears, BS Gill, et al. Genotypic differences in utilization of assimilate sources during maturation of wheat under chronic heat and heat shock stresses. Euphytica. 2002;125(2):179-188.

10. Wahid A, Gelani S, Ashraf M, et al. Heat tolerance in plants: an overview. Environ Exp Bot. 2007;61(3):199-223.

11. Djanaguiraman M, Prasad PVV. Ethylene production under high temperature stress causes premature leaf senescence in soybean. Funct Plant Biol. 2010;37(11):1071-1084.

12. Al-Khatib K, Paulsen GM. Mode of high temperature injury to wheat during grain development. Physiol Plantarum. 1984;61(3):363-368.

13. Grover A, Sabat SC, Mohanty P. Effect of temperature on photosynthetic activities of senescing detached wheat leaves. Plant Cell Physiol. 1986;27:117-126.

14. Wardlaw IF. Temperature control of translocation. In: RL Bielske, et al. editors. Mechanism of regulation of plant growth. Bull. Royal Soc., New Zealand, Wellington; 1974. p. 533-538.

15. Reynolds MP, Delgado MI, Gutiérrez-Rodrígez M, et al. Photosynthesis of wheat in a warm, irrigated environment I. Genetic diversity and crop productivity. Field Crops Res. 2000;66(1):37-50.

16. Al-Khatib K, Paulsen GM. Photosynthesis and productivity during hightemperature stress of wheat genotypes from major world regions. Crop Sci. 1990;30(5):1127-1132.

17. Prasad PVV, Staggenborg SA, Ristic Z. Impacts of drought and/or high temperature stress on physiological, developmental, growth and yield processes of crop plants. In: Ahuja LM, et al, editors. Responses of crops to limited water: Understanding and modeling water stress effects on plant growth processes. Advances in Agricultural Modeling Series, USA; 2008. p. 301-355.

18. Prasad PVV, Pisipati SR, Ristic Z, et al. Impact of nighttime temperature on physiology and growth of spring wheat. Crop Sci. 2008;48(6):23722380 .

19. Blum A. The effect of high temperature stress on wheat leaf and ear photosynthesis. J Exp Bot. 1986;37(1):111-118.

20. Reynolds M, Nagarajan S, Razzaque M, et al. Heat tolerance. In: Reynolds MP, et al, editors. Application of physiology in wheat breeding. CIMMYT, Mexico; 2000. p. 124-135.

21. Farooq M, Bramley H, Palta JA, et al. High temperature stress in wheat during reproductive and grain-filling phases. Crit Rev Plant Sci. 2011;30:491-507.

22. Al-Khatib K, Paulsen GM. High-temperature effects on photosynthetic processes in temperate and tropical cereals. Crop Sci. 1999;39:119-125.

23. Harding SA, Guikema JA, Paulsen GM. Photosynthetic decline from high temperature stress during maturation of wheat. I. Interaction with senescence processes. Plant Physiol. 1990;92(3):648-653.

24. Heckathorn SA, Downs CA, Sharkey TD, et al. The small, methionine-rich chloroplast heat-shock protein protects photosystem II electron transport during high temperature stress. Plant Physiol. 1998;116(1):439-444.

25. Sharkova VE. The effect of heat shock on the capacity of wheat plants to restore their photosynthetic electron transport after photoinhibition or repeated heating. Russ J Plant Physiol. 2001;48:793-797. 
26. Dias AS, Lidon FC. Evaluation of grain filling rate and duration in bread and durum wheat, under high temperature stress after anthesis. J Agron Crop Sci. 2009;195(2):137-147.

27. Xu Q, AQ Paulsen, JA Guikema, et al. Functional and ultrastructural injury to photosynthesis in wheat by high temperature during maturation. Environ Exp Bot. 1995;35(1):43-54.

28. Reynolds MP, Singh RP, Ibrahim A, et al. Evaluating physiological traits to complement empirical selection for wheat in warm environments Euphytica. 1998;100:84-95.

29. Amani I, Fischer RA, Reynolds MP. Canopy temperature depression association with yield of irrigated spring wheat cultivars in a hot climate. J Agron Crop Sci. 1996;176(2):119-129.

30. Ayeneh A, van Ginkel M, Reynolds MP, et al. Comparison of leaf, spike, peduncle and canopy temperature depression in wheat under high temperature stress. Field Crops Res. 2002;79:173-184.

31. Levitt J. Response of plants to environmental stresses. Chilling, freezing and high temperature stresses. I. Academic Press New York; 1980. 497 p.

32. Almeselmani M, Deshmukh PS, Sairam RK. High temperature stress tolerance in wheat genotypes: Role of antioxidant defence enzymes. Acta Agron Hungar. 2009;57:1-14.

33. Almeselmani M, Deshmukh PS, Chinnusamy V. Effect of prolonged high temperature stress on respiration, photosynthesis and gene expression in wheat (Triticum aestivum L.) varieties differing in their thermotolerance. Plant Stress. 2012;6:25-32.

34. Salvucci ME, Crafts-Brandner SJ. Mechanism for deactivation of Rubisco under moderate high temperature stress. Physiol. Plantarum. 2004;122(4):513-519.

35. Lea PJ, Leegood RC. Plant biochemistry and molecular biology, 2nd edition. John Wiley \& Sons, Chichester, UK; 1999. p. 384.

36. Ristic Z, Momcilovic I, Bukovnik U, et al. Rubisco activase and wheat productivity under heat-stress conditions. J Exp Bot. 2009;60:40034014.

37. Demirevska-Kepova K, Holzer R, Simova-Stoilova L, et al. High temperature stress effects on ribulose-1,5-bisphosphate carboxylase oxygenase, Rubisco binding protein and Rubisco activase in wheat leaves. Biol Plant. 2005;49:521-525.

38. Krishnan M, Nguyen HT, Burke JJ. Heat shock protein synthesis and thermal tolerance in wheat. Plant Physiol. 1989;90(1):140-145.

39. Hawker JS, Jenner CF. High temperature affects the activity of enzymes in the committed pathway of starch synthesis in developing wheat endosperm. Aust J Plant Physiol. 1993;20(2):197-209.

40. Keeling PL, Bacon PJ, Holt DC. Elevated temperature reduces starch deposition in wheat endosperm by reducing the activity of soluble starch synthase. Planta. 1993;191(3):342-348.

41. Keeling PL, Banisadr R, Barone L, et al. Effect of temperature on enzymes in the pathway of starch biosynthesis in developing wheat and maize grain. Aust J Plant Physiol. 1994;21(6):807-827.

42. Prakash P, Sharma-Natu P, Ghildiyal MC. High temperature effect on starch synthase activity in relation to grain growth in wheat cultivars. Ind J Plant Physiol. 2003;8:390-398.

43. Shanahan JF, Edwards IB, Quick JS, et al. Membrane thermostaility and heat tolerance of spring wheat. Crop Sci. 1990;30(2):247-251.

44. Fokar M, Nguyen HT, Blum A. Heat tolerance in spring wheat. I. Estimating cellular thermotolerance and its heritability. Euphytica 1998;104(1):1-8.
45. Fokar M, Blum A, Nguyen HT. Heat tolerance in spring wheat. II. Grain filling. Euphytica. 1998;104(1):9-15.

46. Fu J, Momcilovic I, Prasad PVVV. Molecular basis and improvement of heat tolerance in crop plants. In: Josipovic S, et al. editors. High temperature stress: causes, treatment and prevention. Nova Science Publishers, Inc. Hauppauge, New York; 2011. p. 1-23.

47. Ristic Z, Bukovnik U, Prasad PVVV. Correlation between heat stability of thylakoid membranes and loss of chlorophyll in winter wheat under high temperature stress. Crop Sci. 2007;47:2067-2073.

48. Sairam RK, Deshmukh PS, Shukla DS. Tolerance to drought and temperature stress in relation to increased antioxidant enzyme activity in wheat. J Agron Crop Sci. 1987;178(3):171-177.

49. Blum A, Ebercon A. Cell membrane stability as a measure of drought and heat tolerance in wheat. Crop Sci. 1981;21(1):43-47.

50. Kimpel JA, Key JL. Heat shock in plants. Trends Biochem Sci. 1988;10(9):353-357.

51. Ho THD, Sachs MM. Stress-induced proteins: characterization and the regulation of their synthesis. In: A Marcus editor. The Biochemistry of Plants. Academic Press, New York; 1989.

52. Fu J, Momcilović I, Clemente TE, et al. Heterologous expression of a plastid EF-Tu reduces protein thermal aggregation and enhances $\mathrm{CO}_{2}$ fixation in wheat (Triticum aestivum) following exposure to high temperature stress. Plant Mol Biol. 2008;68:277-288.

53. Fu J, Ristic Z. Analysis of transgenic wheat (Triticum aestivum) harboring a maize (Zea mays) gene for plastid EF-Tu: segregation pattern, expression and effects of the transgene. Plant Mol Biol. 2010;73(3):339 347

54. Vierling E. The roles of heat shock proteins in plants. Annu Rev Plant Physiol Plant Mol Biol. 1991;42:579-620.

55. Vierling RA, Nguyen HT. Heat-shock protein gene expression in diploid wheat genotypes differing in thermal tolerance. Crop Sci. 1992;32(2):370-377.

56. Feder ME, Hofmann GE. Heat-shock proteins, molecular chaperones, and the stress response: Evolutionary and ecological physiology. Annu Rev Physiol. 1999;61:243-282.

57. Wang W, B Vinocur, O Shoseyovet et al. Role of plant heat-shock proteins and molecular chaperones in the abiotic stress response. Trends Plant Sci. 2004;9(5):244-252.

58. Hendershot KL, Weng J, Nguyen HT. Induction temperature of heat shock protein synthesis in wheat. Crop Sci. 1992;32(1):256-261.

59. Ristic Z, Bukovnik U, Momcilovic I, et al. Heat induced accumulation of chloroplast protein synthesis elongation factor, EF-Tu, in winter wheat. $J$ Plant Physiol. 2008;165:192-202.

60. Rao D, Momcilovic I, Kobayashi S, et al. Chaperone activity of recombinant maize chloroplast protein synthesis elongation factor, EFTu. Eur J Biochem. 2004;271(18):3684-3692.

61. Schoffl F, Prandl R, Reindl A. Molecular responses to high temperature stress. In: K Shinozaki, et al. editors. Molecular responses to cold drought, heat and salt stress in higher plants. KRG. Landes Co, Austin; 1999. p. 81-98.

62. Sairam RK, Srivastava GC, Saxena DC. Increased antioxidant activity under elevated temperatures: a mechanism of high temperature stress tolerance in wheat genotypes. Biol Plantarum. 2000;43(2):245-251.

63. Salin ML. Chloroplast and mitochondrial mechanism for protection against oxygen toxicity. Free Rad Res. 1991;13:851-858. 
64. Agarwal S, Sairam RK, Srivastava GC, Changes in antioxidant enzymes activity and oxidative stress by abscisic acid and salicylic acid in wheat genotypes. Biol Plant. 2005;49(4):541-550.

65. Diego AM, Oliva MA, Carlos AM, et al. Photosynthesis and activity of superoxide dismutase, peroxidase and glutathione reductase in cotton under salt stress. Environ Exp Bot. 2003;49:69-76.

66. Dat JF, Foyer CH, Scott IM. Changes in salicylic acid and antioxidants during induced thermotolerance in mustard seedlings. Plant Physiol. 1998;118(4):1455-1461.

67. Dat JF, Lopez-Delgado $\mathrm{H}$, Foyer $\mathrm{CH}$, et al. Parallel changes in $\mathrm{H}_{2} \mathrm{O}_{2}$ and catalase during thermotolerance induced by salicylic acid or heat acclimation in mustard seedlings. Plant Physiol. 1998;116(4):13511357.

68. Djanaguiraman M, Sheeba JA, Devi DD, et al. Cotton leaf senescence can be delayed by nitrophenolate spray through enhanced antioxidant defense system. J Agron Crop Sci. 2009;195:213-224.

69. Djanaguiraman M, Prasad PV, Seppanen M. Selenium protects sorghum leaves from oxidative damage under high temperature stress by enhancing antioxidant defense system. Plant Physiol Biochem. 2010;48(12):9991007.

70. Djanaguiraman M, Sheeba JA, Devi DD, et al. Nitrophenolates spray can alter boll abscission rate in cotton through enhanced peroxidase activity and increased ascorbate and phenolics levels. J Plant Physiol. 2010;167(1):1-9.

71. Fitter AH, Hay RKM. Environmental Physiology of Plants. Academic Press, London; 1987.

72. Imlay JA, Linns S. DNA damage and oxygen radical toxicity. Science. 1988;240(4857):1302-1309.

73. Paliyath G, Droillard MJ. The mechanism of membrane deterioration and disassembly during senescence. Plant Physiol Biochem. 1992;30:789812 .

74. Noctor G, Foyer CH. Ascorbate and glutathione: keeping active oxygen under control. Annu Rev Plant Physiol Plant Mol Biol. 1998;49:249-279.

75. Liu $X$, Huang B. High temperature stress injury in relation to membrane lipid peroxidation in creeping bentgrass. Crop Sci. 2000;40:503-510.

76. Prochazkova D, Sairam RK, Srivastava GC, et al. Oxidative stress and antioxidant activity as the basis of senescence in maize leaves. Plant Sci. 2001;161:765-771.

77. Srivalli B, Khanna Chopra R. The developing reproductive 'sink' induces oxidative stress to mediate nitrogen mobilization during monocarpic senescence in wheat. Biochem Biophys Res Commun. 2004;325(1):198202 .

78. Viswanathan C, Khanna-Chopra R. Effect of high temperature stress on grain growth, starch synthesis and protein synthesis in grains of wheat (Triticum aestivum L.) varieties differing in grain weight stability. $J$ Agron Crop Sci. 2001;186(1):1-7.

79. Kraus TE, McKersie BD, Fletcher RA. Paclobutrazol-induced tolerance of wheat leaves to paraquat may involve increased antioxidant enzyme activity. J Plant Physiol. 1995;145(4):570-576.

80. Krause GH, Weis E. Chlorophyll fluorescence as a tool in plant physiology: II. Interpretation of fluorescence signals. Photosynth Res. 1984;5(2):139-157.

81. Bhullar SS, Jenner CF. Differential responses to high temperatures of starch and nitrogen accumulation in the grain of four cultivars of wheat. Austr J Plant Physiol. 1985;12(4):363-375.
82. Blum A, Sinmena B, Mayer J, et al. Stem reserve mobilization supports wheat-grain filling under high temperature stress. Aust J Plant Physiol. 1994;21(6):771-781.

83. Narayanan S, Tamura PJ, Roth MR, et al. Wheat leaf lipids during heat stress: I. High day and night temperatures result in major lipid alterations. Plant Cell Environ. 2016;39(4):787-803.

84. Narayanan S, Prasad PVVV, Welti R. Wheat leaf lipids during heat stress: II. Lipids experiencing coordinated metabolism are detected by analysis of lipid co-occurrence. Plant Cell Environ. 2016;39:608-617.

85. Narayanan S, Prasad PVVV, Welti R. Alterations in wheat pollen lipidome during high day and night temperature stress. Plant Cell Environ. 2018.

86. Blum A, Klueva N, Nguyen HT. Wheat cellular thermotolerance is related to yield under high temperature stress. Euphytica. 2011;117(2):117-123.

87. Slafer GA, Rawson HM. Base and optimum temperatures vary with genotype and stage of development in wheat. Plant Cell Environ. 1995;18(6):671-679.

88. Johnson RC, Kanemasu ET. Yield and development of winter wheat at elevated temperatures. Agron J. 1983;75:561-565.

89. Wollenweber B, JR Porter, J Schellberg. Lack of interaction between extreme high-temperature events at vegetative and reproductive growth stages in wheat. J Agron Crop Sci. 2003;189(3):142-150.

90. Hall AE. Breeding for heat tolerance. Plant Breed Rev. 1992;10:129-168.

91. Hall AE. Physiology and breeding for heat tolerance in cowpea, and comparison with other crops. CG Kuo, editor. Adaptation of food crops to temperature and water stress. 1993. p. 93-410.

92. Saini HS, Aspinall D. Abnormal sporogenesis in wheat (Triticum aestivum L.) induced by short periods of high temperatures. Ann Bot. $1982 ; 49(6) 835-846$.

93. Saini HS, Sedgley M, Aspinall D. Effect of high temperature stress during floral development on pollen tube growth and ovary anatomy in wheat (Triticum aestivum L.). Aust J Plant Physiol. 1983;10(2):137-144.

94. Saini HS, Sedgley M, Aspinall D. Developmental anatomy in wheat of male sterility induced by high temperature stress, water deficit or abscisic acid. Aust J Plant Physiol. 1984;11(4):243-253.

95. Jager K, Fabian A, Barnabas B. Effect of water deficit and elevated temperature on pollen development of drought sensitive and tolerant winter wheat (Triticum aestivum L.) genotypes. Acta Biol Szegediensis. 2008;52(1):67-71

96. Young TE, J Ling, J Geisler-Lee, et al. Developmental and thermal regulation of the maize heat shock protein, HSP101. Plant Physiol. 2001;127(3):777-791.

97. Russell G, Wilson GW. An agri-pedo-climatological knowledge base of wheat in Europe. Joint Research Centre, EU, Luxembourg; 1994. 158 p.

98. Hays DB, Do JH, Mason RE, et al. High temperature stress induced ethylene production in developing wheat grains induces kernel abortion and increased maturation in a susceptible cultivar. Plant Sci. 2007; 172:1113-1123.

99. Evans LT. The influence of irradiance before and after anthesis on grain yield and its components in microcrops of wheat grown in a constant day length and temperature regime. Field Crops Res. 1978;1:5-19.

100. Wheeler TR, GR Battsa, RH Ellisa, et al. Growth and yield of winter wheat (Triticum aestivum) crops in response to $\mathrm{CO}_{2}$ and temperature. The Journal of Agricultural Science. 1996;127(1):37-48. 
101. Shpiler L, Blum A. Heat tolerance for yield and its components in different wheat cultivars. Euphytica. 1991;51(3):257-263.

102. Shpiler L, Blum A. Differential reaction of wheat cultivars to hot environments. Euphytica. 1986;35(2):483-492.

103. Blumenthal CS, Barlow EWR, Wrigley CW. Growth environment and wheat quality: the effect of high temperature stress on dough properties and gluten proteins. J Cereal Sci. 1993;18:3-21.

104. Stone PJ, Nicolas ME. Comparison of sudden high temperature stress with gradual exposure to high temperature during grain-filling in two wheat varieties difference in heat tolerance. II. Fractional protein accumulation. Aust J Plant Physiol. 1998;25:1-11.

105. Warrington IJ, RL Dunstone, LM Green. Temperature effects at three developmental stages on the yield of the wheat ear. Aust J Agr Res. 1977;28(1):11-27.

106. Hoshikawa K. Studies on ripening of wheat grain: 4. Influence of temperature upon the development of endosperm. Proc Crop Sci. Soc Jpn. 1962;30:228-231.

107. Sofield I, Evans LT, Cook MG, et al. Factors influencing the rate and duration of grain filling in wheat. Aust J Plant Physiol. 1977;4:785-797.

108. Lobell DB, Ortiz-Monasterio IJ, Asner GP, et al. Analysis of wheat yield and climatic trends in Mexico. Field Crops Res. 2005;94:250-256.

109. Spiertz JHJ, Hamer RJ, Xu H, C, et al. High temperature stress in wheat (Triticum aestivum L.): Effects on grain growth and quality traits. Eur $J$ Agron. 2006;25:89-95.

110. Skovmand B, Rajaram S, Ribaut JM, e al. Wheat genetic resources. In $\mathrm{BC}$ Curtis, et al. editors. Bread wheat improvement and production. FAO, Rome, Italy; 2012. p. 89-102.

111. Wardlaw IF, I Sofield, PM Cartwright. Factors limiting the rate of dry matter accumulation in the grain of wheat grown at high temperature. Aust J Plant Physiol. 1980;7(4):387-400.

112. Wardlaw IF, IA Dawson, P Munibi, et al. The tolerance of wheat to high temperatures during reproductive growth. I. Survey procedures and general response patterns. Aust J Agric Res. 1989a ;40(1):1-13.

113. Wardlaw IF, IA Dawson, P Munibi. The tolerance of wheat to high temperatures during reproductive growth. II. Grain development. Aust $J$ Agric Res. 1989b;40(1):15-24.

114. Ferrara GO, Rajaram S, Mosaad MG. Breeding strategies for improving wheat in heat-stressed environments. In: Saunders DA, et al, editors. Wheat in heat-stressed environments: Irrigated, dry areas and ricewheat farming systems. CIMMYT, Mexico; 1994. p. 25-32.

115. Damania AB, Tahir M. Heat and cold tolerance in wild relatives and primitive forms of wheat. In: Damania $\mathrm{AB}$ editor. Biodiversity and wheat improvement. John Wiley \& Sons, Chichester, West Sussex, UK; 1993 p. $217-224$.

116. Ehdaie B, Waines JG. Heat resistance in wild Triticum and Aegilops. $J$ Gene Breed. 1992;46:221-228.

117. Zaharieva M, E Gaulin, M Havaux, et al. Drought and heat responses in the wild wheat relative Aegilops geniculata Roth: Potential interest for wheat improvement. Crop Sci. 2001;41(4):1321-1329.

118. Trethowan RM, Mujeeb-Kazi A. Novel germplasm resources for improving environmental stress tolerance of hexaploid wheat. Crop Sci. 2008;48(4):1255-1265.

119. Kurahashi Y, Terashima A, Takumi S. Variation in dehydration tolerance, ABA sensitivity and related gene expression patterns in
D-genome progenitor and synthetic hexaploid wheat lines. Int J Mol Sci. 2009;10(6):2733-2751

120. Siddiqui KA. Synthetic amphyploids in breeding-genetic and evolutionary studies in wheat. In: A Muhammed, et al. editors. Genetic diversity in plants. Plenum Press, New York, NY; 1976. p. 97-102.

121. Rajaram S, Mujeeb-Kazi A, Singh RP. Wheat (Triticum asetivum). PN Bahl, editor. Genetics, cytogenetics and breeding of crop plants. Scientific Publishers, Enfield, NH; 1977. p. 77-144.

122. Tewolde H, Fernandez CJ, Erickson CA. Wheat cultivars adapted to postheading high temperature stress. J Agron Crop Sci. 2006;192(2):111-120.

123. Sheehy JE, Mabilangan AE, Dionora KJA, et al. Time of day of flowering in wild species of the genus Oryza. Int Rice Res Notes. 2007;32:12-13.

124. Nishiyama I, Blanco L. Avoidance of high temperature sterility by flower opening in the early morning. JARQ. 1980;14(2):116-117.

125. Ibrahim AMH, Quick JS. Genetic control of high temperature tolerance in wheat as measured by membrane thermal stability. Crop Sci. 2001;41:1405-1407.

126. Maxwell K, Johnson GN. Chlorophyll fluorescence: A practical guide. $J$ Exp Bot. 2000;51(345):659-668.

127. Ferris R, Ellis RH, Wheeler TR, et al. Effect of high temperature stress at anthesis on grain yield and biomass of field-grown crops of wheat. Ann Bot. 1998;82(5):631-639.

128. Fischer RA. Number of kernels in wheat crops and the influence of solar radiation and temperature. J Agric Sci. 1985;105:447-461.

129. Fischer RA, Maurer R. Drought resistance in spring wheat cultivars. I Grain yield responses. Aust J Agric Res. 1978;29(4):897-912.

130. Gill BS, Friebe B. Cytogenetics, phylogeny and evolution of cultivated wheats. BC Curtis, editor. Bread wheat improvement and production. FAO, Rome, Italy; 2002. p. 71-88.

131. Asian Vegetable Research and Development Center, Shanhua, Taiwan; 1971, p. 271-284.

132. Hurkman WJ, McCue KF, Altenbach SB, et al. Effect of temperature on expression of genes encoding enzymes for starch biosynthesis in developing wheat endosperm. Plant Sci. 2003;164:873-881.

133. Keles Y, Oncel I. Response of antioxidative defense system to temperature and water stress combinations in wheat seedlings. Plant Sci. 2002; 163:783-790.

134. Khanna-Chopra R, Viswanathan C. Evaluation of high temperature stress tolerance in irrigated environment of T. aestivum and related species. I. Stability in yield and yield components. Euphytica. 1999;106:169-180.

135. Lu Z, Percy RG, Qualset CO, et al. Stomatal conductance predicts yields in irrigated Pima cotton and bread wheat grown at high temperatures. $J$ Exp Bot. 1998;49:543-560.

136. Mac Dowall FDH. Growth kinetics of Marquis wheat V. Morphogenic dependence. Can J Bot. 1973;51(7):1259-1265.

137. Pradhan GP, Prasad PVVV, Fritz AK, et al. High temperature tolerance in Aegilops species and its potential transfer to wheat. Crop Sci. 2012;52:292-304.

138. Prasad PVV, Boote KJ, Allen LH, et al. Species, ecotype and cultivar differences in spikelet fertility and harvest index of rice in response to high temperature stress. Field Crops Res. 2006;95:398-411.

139. Raychaudhuri SS. The role of superoxide dismutase in combating oxidative stress in higher plants. Bot Rev. 2000;66(1):89-98. 
140. Reynolds MP, Balota M, Delgado MIB, et al. Physiological and morphological traits associated with spring wheat yield under hot irrigated conditions. Aust J Plant Physiol. 1994;21(6):717-730.

141. Sairam RK, Srivastava GC. Changes in antioxidant activity in subcellular fractions of tolerant and susceptible wheat genotypes in response to long term salt stress. Plant Sci. 2002;162:897-904.

142. Sayed OH. Chlorophyll fluorescence as a tool in cereal crop research Photosynthetica. 2003;41(3):321-330.

143. Stone PJ, Nicolas ME. Wheat cultivars vary widely in their responses of grain yield and quality to short periods of post anthesis high temperature stress. Aust J Plant Physiol. 1994;21(6):887-900.

144. Stone PJ, Nicholas ME. Comparison of sudden high temperature stress with gradual exposure to high-temperature during grain filling in two wheat varieties differing in heat tolerance. 1. Grain growth. Aust J Plant Physiol. 1995;22:935-944.
145. Stone PJ, Gras PW, Nicolas ME. The influence of recovery temperature on the effects of a brief heat shock on wheat. III. Grain protein composition and dough properties. J Cereal Sci. 1997;25:129-141.

146. Streck NA. Climate change and agroecosystems: the effect of elevated atmospheric $\mathrm{CO}_{2}$ and temperature on crop growth, development and yield. Ciencia Rural. 2005;35:730-740.

147. Sun QX, Xu RQ. Genetic control of tolerance to high temperature stress in wheat. AE Slinkard, editor. Proceedings of the 9th International Wheat Genetics Symposium. Saskatoon, Canada; 1998. p. 236-244.

148. Waines JG. High temperature stress in wild wheats and spring wheats. Aust J Plant Physiol. 1994;21:705-715. 